\title{
Fixation of dormant tilletia teliospores for thin sectioning
}

John Scott Gardner

Brigham Young University - Provo

\section{BYU ScholarsArchive Citation}

Gardner, John Scott, "Fixation of dormant tilletia teliospores for thin sectioning" (1976). Theses and Dissertations. 8058.

https://scholarsarchive.byu.edu/etd/8058

This Thesis is brought to you for free and open access by BYU ScholarsArchive. It has been accepted for inclusion in Theses and Dissertations by an authorized administrator of BYU ScholarsArchive. For more information, please contact ellen_amatangelo@byu.edu. 


\author{
A Thesis \\ Presented to the \\ Department of Botany and Range Science \\ Brigham Young University
}

\author{
In Partial Fulfillment \\ of the Requirements for the Degree \\ Master of Science
}

by

John S. Gardner

April 1976 
TABLE OF CONTENTS

LIST OF FIGURES . . . . . . . . . . . . . iv

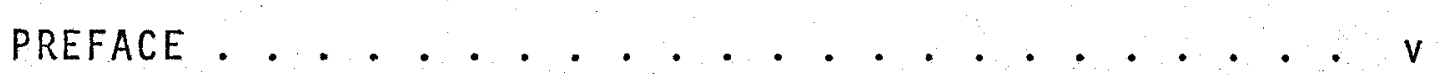
INTRODUCTION . . . . . . . . . . . . . . 1 MATERIALS AND METHODS ............... 2 RESULTS AND DISCUSSION $, \cdot \ldots, \ldots$ LITERATURE CITED •. . . . . . . . . . 6

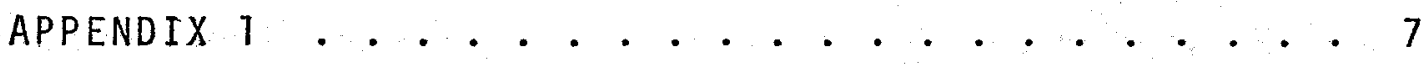

Introduction .............. 8

Materials and Methods............. . 9

Results and Discussion . . . . . . . . . . 11

Literature cited . . . . . . . . . 22 APPENDIX 2 . . . . . . . . . . . . 23

Literature Review . . . . . . . . . . 24

Literature Cited . . . . . . . . . . 31 
Figure

Main Text

1. Thin section of a prefixed dormant teliospore of Tilletia caries ............. . . 5

2. Thin section of a non-prefixed dormant teliospore of Tilletia caries.......... . 5

Appendix 1

1. Thin section of a portion of a germinating teliospore of Tilletia caries . . . . . . . 12

2. Freeze-etching replica of a dormant Tilletia caries teliospore............. 13

3. Thin section of an organelle fraction prepared from dormant teliospores . . . . . . . 14

4. Thin section of a lipid body of a dormant teliospore :. . . . . . . . . . 16

5. Thin section of a lipid body of a dormant teliospore showing a "mop-like" structure . . 17

6. Thin section of a dormant teliospore which had not undergone the prefixation treatment . . . 18

7. Thin section of a lipid body of a dormant teliospore which was not prefixed . . . . . 20

8. Thin section of a lipid body of a germinating teliospore which was not prefixed . . . . . 21 


\section{PREFACE}

The main body of this thesis has been published (Stain Technology $50: 347-350,1975)$. Some preliminary results of a study on Tilletia caries teliospores using the method presented in the main text are presented in appendix 1. Appendix 2 contains a condensed review of a small portion of the literature reviewed during this study.

The author wishes to express his appreciation to Dr. H. M. Hess, Department of Botany and Range Science, Brigham Young University for his support, encouragement and helpful instruction in the completion of this manuscript and research.

Sincere thanks is also given to Mrs. Connie Swensen for her assistance in the laboratory and to the Department of Botany and Range Science in general for the financial support which made the completion of this degree possible.

Deep appreciation is expressed to my wife. Without her support and encouragement this study would not have been completed. 


\section{INTRODUCTION}

Surface features of dormant fungal spores may be examined by scanning electron microscopy, and both surface and internal characteristics may be inyestigated by freeze-etching. However, many dormant fungal spores have spore walls which are impervious to fixatives and resins used for thin sectioning investigations, including the very fluid Spurr resin (7).

Ekundayo (2) broke Rhizopus arrhizus sporangiospores in fixative with a Mickle disintegrator and Lowry and Sussman (5) fixed dormant ascospores of Neurospora tetrasperma by cracking them in fixative between pieces of plate glass. These methods as well as sonication and the rupturing of frozen spore suspensions be forcing them through a small orifice with a hydrolic press, were not successful with Tilletia teliospores which have walls ranging from less than 2 um to more than 3 um in thickness.

This study reports a procedure for successful fixation of dormant fungal spores while cutting or fracturing frozen spore samples with an ultramicrotome equipped with a cold stage. 
MATERIALS AND METHODS

Tilletia caries (DC.) Tul. (race T-16) teliospores were supplied by E. J. Trione (Oregon State University, Corvallis, Oregon). Dormant teliospores were frozen in liquid freon rather than liquid nitrogen to minimize ice crystal formation and to prevent artifact formation. These freezing procedures are identical to the procedures used for freeze-etching (1) except in this investigation the spores were frozen onto specimen chucks of an FTS Sorval1-Christensen frozen thin sectioner attached to a Sorva11 MT-2B Porter-Blum ultramicrotome. Samples were frozen and cut or fractured in distilled water or they were placed in glutaraldehyde-acrolein buffered with sodium cacodylate (pH 7.2) for at least 24 hours, and cut or fractured in fixative. Specimens were cut from $-20 \mathrm{C}$ to $-75 \mathrm{C}$ at thickness settings of 10 , 15, 20 and $25 \mu \mathrm{m}$ (average spore diameter ca. $18 \mu \mathrm{m}$ ). The specimens were cut with glass knives which were changed frequently to insure sharp edges for cutting. The cut or fractured material accumulated in the empty boat as a frozen mass with a powdery appearance. A brush moistened with fresh fixative was used to transfer the cut or fractured spores to fresh fixative. The cut or fractured spores were processed for thin sectioning following the procedures of Hess (3) which consisted of fixation in glutaraldehyde-acrolein buffered with sodium cacodylate $(\mathrm{pH} 7.2)$ for at least 2 hours at $22 \mathrm{C}$. Spores were treated with osmium in the same buffer for 2 hours in an ice bath, dehydrated and embedded in Spurr (7) resin. 


\section{RESULTS AND DISCUSSION}

Dormant Tilletia caries teliospores placed in fixative for 24 hours or longer, frozen in liquid freon, cut or fractured with an ultramicrotome and processed for thin sectioning have an ultrastructure similar to germinated teliospores (Fig. 1). Dormant spores have readily distinguishable lipid bodies, nuclei with distinct nucleoli, the plasma membrane is distinct and the organization of the cytoplasm may be readily observed. Conversely, dormant teliospores processed without prior freezing and cutting are usually devoid of cytoplasm and often the inner spore wall layer is swept away during sectioning (Fig. 2). In some instances the cytoplasm is retained as an amorphous mass devoid of details.

Liquid freon has been used for rapid freezing of biological specimens for freeze-etching investigations for many years (6) and for freeze-etching investigations of some dormant fungal spores (4). Dormant spores survive the freezing treatment (4), perhaps because surfaces are rapidiy wet and freezing is rapid. Whether the spores were cut or fractured is unclear by examination of the thin sections, however, spores sectioned easier at higher temperatures $(-20$ to $-30 \mathrm{C})$. At -60 to $-75 \mathrm{C}$ the spore samples tended to chip or fracture. These differences in cutting or fracturing properties may be significant for some kinds of spores.

At the 10 um setting all spores were cut or fractured whereas at $25 \mu \mathrm{m}$ a relatively small percentage of the spores were cut or 
fractured. At 20 um only occasional spores were not cut or fractured. Adequate cutting or fracturing and preservation of teliospores was obtained at 15-20 um. Thicker settings may be necessary to cut or fracture germinating spores to compensate for spore swelling.

It may be desirable to cut away only a portion of the spore wall so that the cytoplasm is undisturbed, and fixative is allowed to penetrate the cytoplasm. It is not possible to accomplish this with more than a yery smal1 percentage of spores.

Several attempts were made to cut or fracture dormant teliospores in distilled water followed by fixation. The spores could not be adequately fixed. The spores must be in fixatiye before cutting or fracturing. The preseryation of ultrastructural details in dormant spores frozen and sectioned in fixative, gives significant information about the cytoplasm.

Hess (4) found that freeze-etching proyided a means to investigate dormant spores; after spores germinated both thin sectioning and freeze-etching may be used. Out process of thin sectioning dormant spores makes it possible to observe organelles of dormant spores and stain for enzyme systems still active after the spores are fixed with buffered aldehydes. Thus, histochemical investigations previously not possible with dormant spores may now be conducted and organelle changes may be followed during development.

Some preliminary results of a study of Tilletia caries teliospores using this method are presented in appendix 1. Appendix 2 contains the required literature review. 


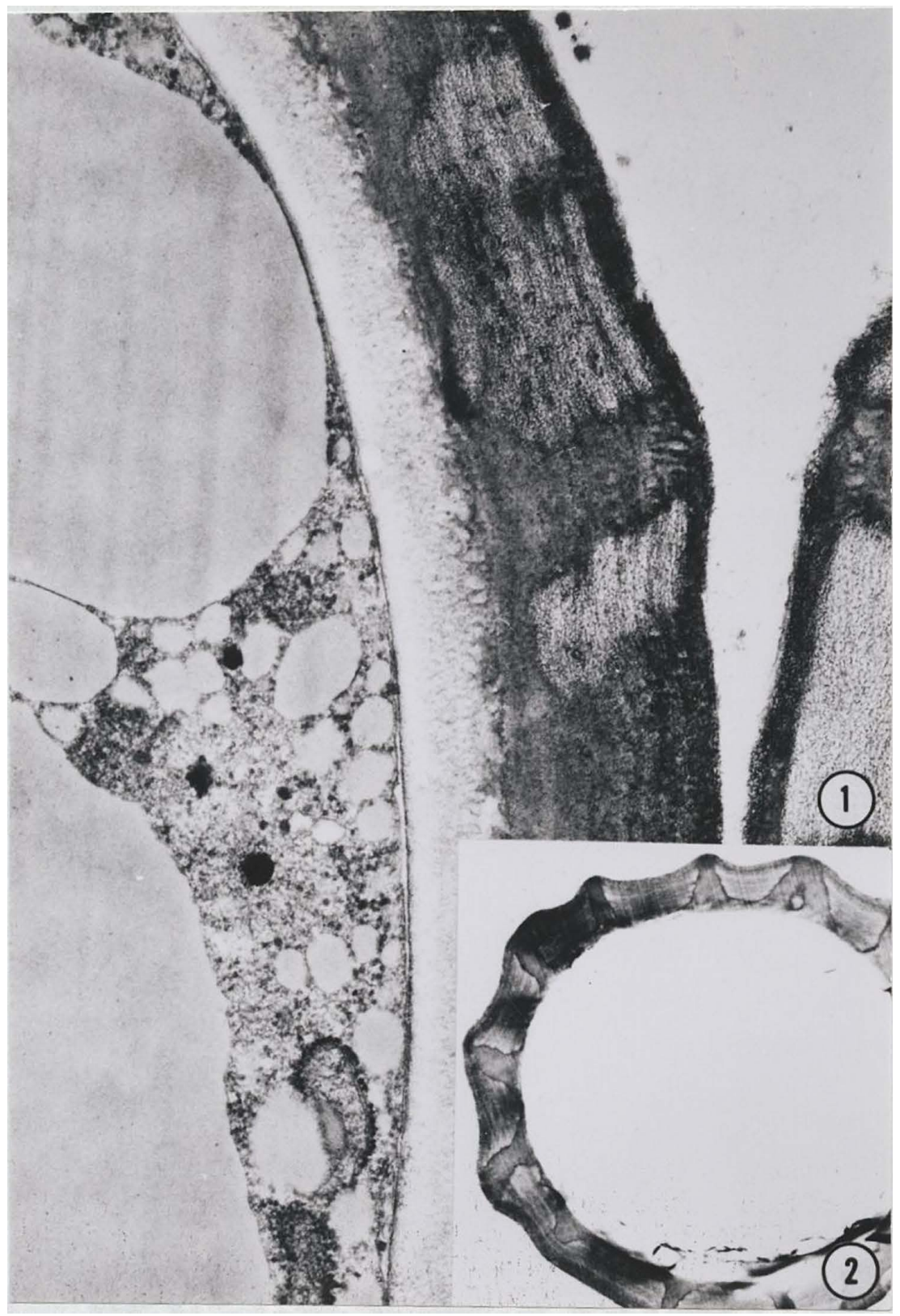

Figs. 1, 2. Thin sections of dormant Tilletia caries teliospores. Fig. 1. This section of a portion of a spore placed in sodium cacodylate buffered glutaraldehyde-acrolein and frozen in liquid freon. Subsequently the sample was sectioned on a cold stage on an ultramicrotome and processed for thin sectioning by standard procedures. X22,000. Note that spore contents are well preserved. Fig. 2. Thin section of an intact dormant spore with standard fixation and embedding techniques. $\times 3,400$. Note that the contents of the spore were lost during sectioning. 


\section{LITERATURE CITED}

1. Allen, J. V., Hess, W. M., and Weber, D. J. 1971. Ultrastructural investigations of dormant Tilletia caries teliospores. Mycologia 63:144-156.

2. Ekundayo, E. 1966. Further studies on germination of sporangiospores of Rhizopus arrhizus. J. Gen. Microbio1. 42:283-290.

3. Hess, W. M. 1966. Fixation and staining of fungus hyphae and host plant root tissue for electron microscopy. Stain Tech. $41: 27-35$.

4. Hess, W. M. 1973. U7trastructure of fungal spore germination. Shokubutsu Byogai Kenkyu (Forsch. Gebiet Pflanzenkrankh.), Kyoto $8: 71-84$.

5. Lowry, R. J. and Sussman, A. S. 1968. U1 trastructural changes during germination of ascospores of Neurospora tetrasperma.

J. Gen. Microbio1. 51:403-409.

6. Moor, H. and Muhlethaler, K. 1963. Fine structure in frozenetched yeast cells. J. Cell Biol. 17:609-628.

7. Spurr, A. R. 1969. A low-viscosity epoxy resin embedding medium for electron microscopy. J. Ultrastruct. Res. 26:31-43. 


\section{APPENDIX 1}

PRELIMINARY STUDIES OF LIPID BODIES OF DORMANT TILLETIA CARIES TELIOSPORES 


\section{INTRODUCTION}

Al though both surface and internal characteristics of dormant fungal spores have been investigated by the use of freeze-etching, relatively few thin section studies have been conducted on dormant spores which have thick walls. This is due to the impenetrability of the walls to fixatives or embedding media or both. Recently Gardner et al. (4) reported a means of processing dormant Tilletia caries teliospores for thin sectioning. By use of this technique, ultrastructural changes during the germination of teliospores of Tilletia caries have been studied.

Dormant teliospores of the genus Tilletia contain high concentrations of lipids. This report presents new information about the lipid bodies found in dormant and germinating Tilletia caries teliospores. 
MATERIALS AND METHODS

Tilletia caries (DC.) Tul. (race T-16) teliospores were kindly supplied by E. J. Trione (Oregon State University, Coryallis, Oregon). In all freeze-etching and thin sectioning experiments performed, the dormant and germinating teliospores were frozen in liquid freon to minimize ice crystal formation and to prevent the formation of artifacts. Freeze-etching replicas of dormant teliospores were prepared by the methods of Allen et al. (1).

To obtain synchronous germination of the teliospores, a modified method of Trione (personal communication) was used. Dormant teliospores $(0.5 \mathrm{gm})$ were placed in an Erlenmeyer flask containing $50 \mathrm{ml}$ of distilled water and incubated on a rotary shaker in the dark at $6-8 \mathrm{C}$ for 216 hours. At various intervals $(0,6,12,24,120,216$ hours) samples were collected and prepared for thin sectioning.

Two different methods for preparing thin sections (Gardner et al., 4) were used for spore samples collected at each time interval. The first involved placing the haryested spores directly into buffered glutaraldehyde-acrolein fixative for at least 24 hours prior to further handling. The second method involved no prefixation. Following prefixation, or lack of it, the two methods were identical. Spores were frozen, either in their fixative solution or water, onto the specimen chuck of an FTS Sorvall-Christensen frozen thin sectioner attached to a Sorval1 MT-2B Porter-Blum ultramicrotome by using liquid freon. Specimens were then sectioned at 20 um intervals at $-70 \mathrm{C}$. 
The sectioned material accumulated on the back of the knife in the empty boat as a frozen mass with a powdery appearance. A brush moistened with fresh fixative was used to transfer the sectioned spores to fresh fixative. The sectioned spores were processed for thin sectioning investigations by the procedures described by Hess (6). 


\section{RESULTS AND DISCUSSION}

Spherosomes or lipid bodies are intracellular oil-containing particles that have been observed by plant cytologists for more than a half century (3). Although many ultrastructural investigations have been conducted with these organelles, their cytological status remains uncertain.

Various techniques have been used to investigate the morphology of lipid bodies. Three basic approaches have been utilized; thin sectioning $(8,9)$; Freeze-etching (1); and application of chemicals to the sample either for histochemical purposes or for extraction of the contents of these organelles as a part of the ultrastructural investigation $(7,10)$.

Thin section investigations of lipid bodies typically reveal a. uniformly osmiophilic matrix in dormant and germinating teliospores prefixed with buffered glutaraldehyde-acrolein (Fig. 1).

The appearance of lipid bodies in frozen-etched specimens depends upon the random plane of fracturing. In surface views these lipid bodies commonly have associated depressions and protuberances (1). Cross-fractures through lipid bodies of these teliospores do not reveal substructure (Fig. 2).

Various lipid extraction techniques have been used to investigate the membrane surrounding the lipid body. Yatsu and Jacks (10) defatted spherosomes and found that the contents of the spherosomes were removed leaving a circular electron-transparent area bounded by 


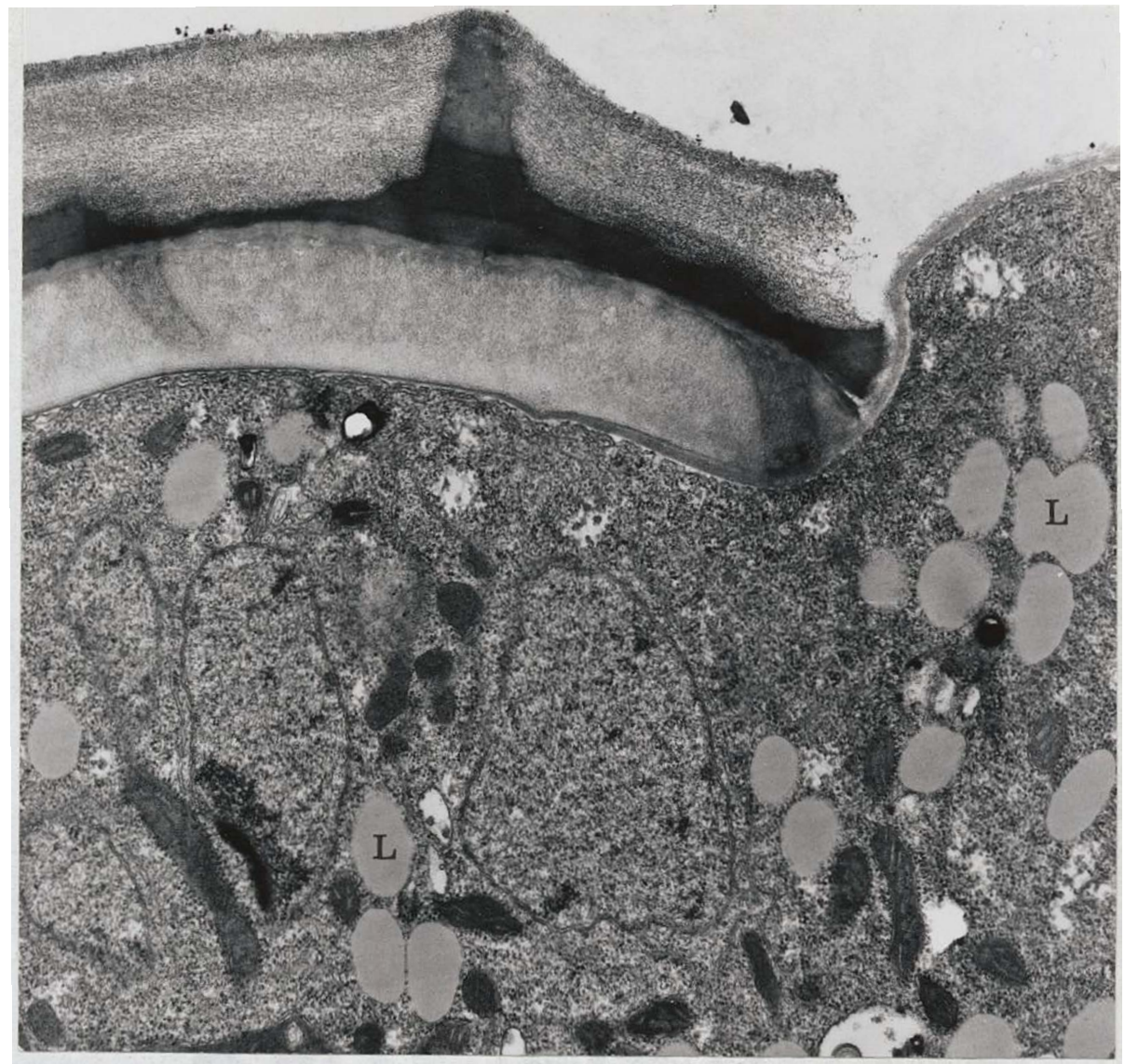

Fig. 1. Thin section of a portion of a germinating tel iospore of Tilletia caries. X18,400. Note the uniformly osmiophilic matrix within the lipid bodies (L). 


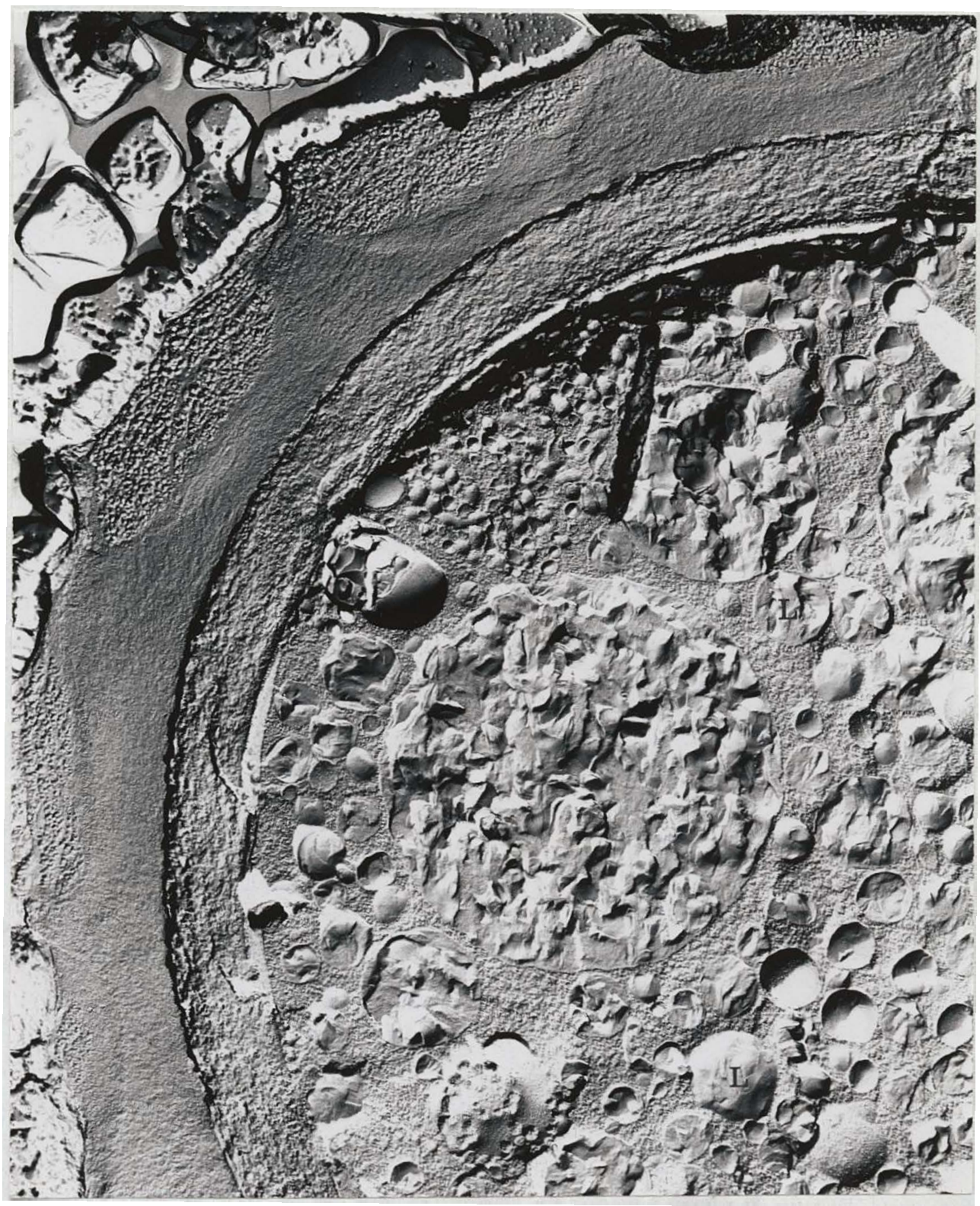

Fig. 2. Freeze-etch replica of a dormant Tilletia caries teli ospore. X27,500. Note the spherical appearance of the 7ipid bodies ( $L$ ) and the apparent amorphous nature of their contents (1ack of visible substructure). 


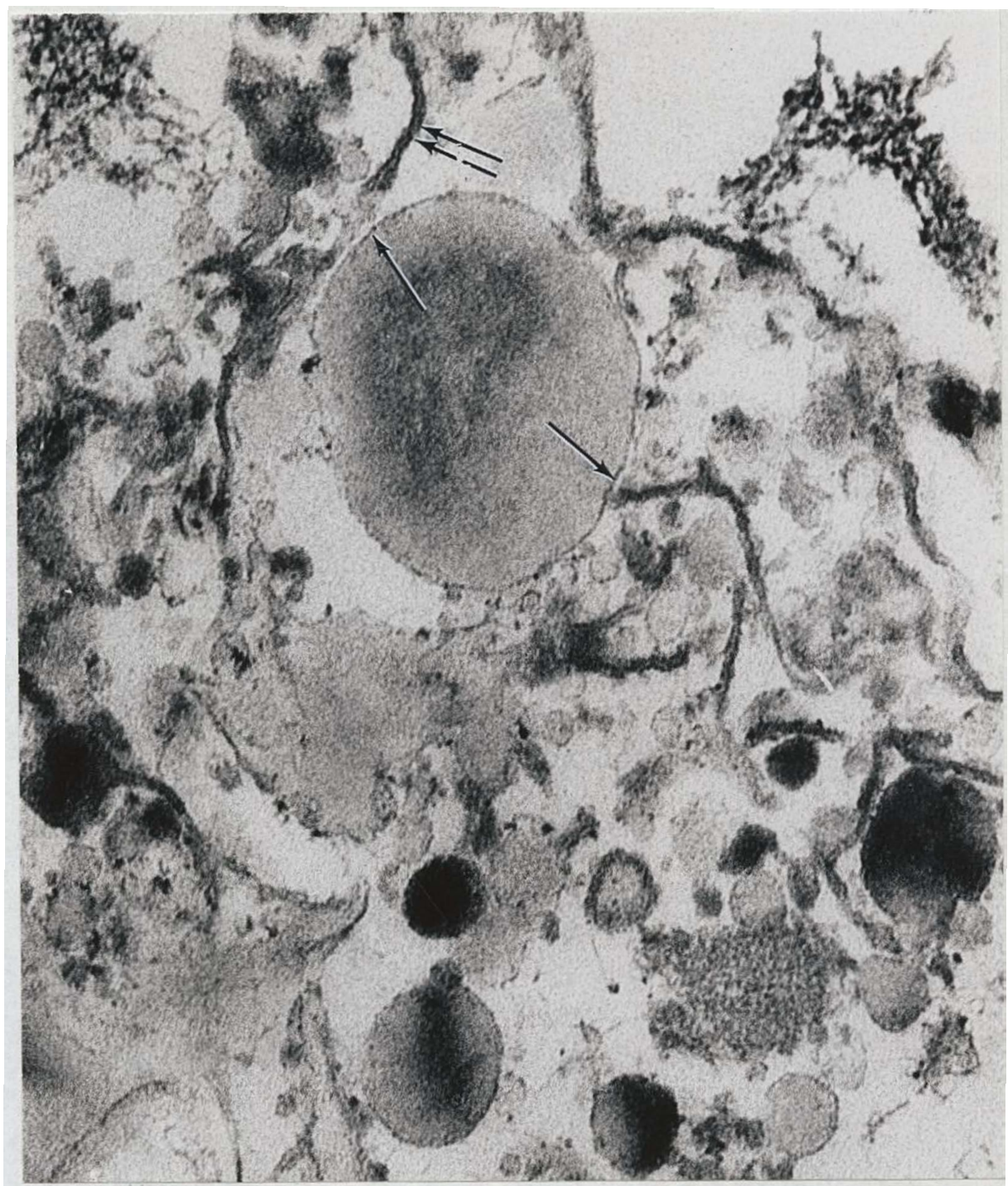

Fig. 3. Thin section of a fraction of dormant teliospores prepared by rupturing by forcing them through a small orifice under pressure. $\times 100,000$. Note the half-unit membrane surrounding the lipid body (single arrow) compared with unit membrane (double arrows). 
a single fine line. These electron dense lines were assumed to be half-unit membranes. The lipid bodies in teliospores of Tilletia caries appear to have a typical half-unit membrane surrounding them (Fig. 3).

Very few reports have been submitted which indicate that there is substructure within lipid bodies. Buttrose and Swift (2) have shown that there are gaseous inclusions within the lipid bodies of several different plant seeds. There has been no report of substructure or inclusions within the lipid bodies of Tilletia teliospores. However, there are frequent irregular electron dense and electron opaque areas evident within lipid bodies of developing and germinating Tilletia caries and Tilletia controversa teliospores (5). These irregular electron dense patterns are evident in dormant and germinating teliospores which have been subjected to the prefixation treatment of buffered glutaraldehyde-acrolein fixative (Fig. 4). It is only infrequently that the "mop-like" structure appears in spores which have undergone this treatment (Fig. 5). However, when the teliospores were frozen to the specimen chucks in distilled water and did not undergo the prefixation treatment prior to frozen sectioning, extremely pronounced "mop-like" structures were evident within the lipid bodies (Fig. 6). These substructures were observed in all samples collected at each of the incubation times from dormancy to the fully germinated spores.

The "mop-like" structures are made up of a lamellar substructure with 6-10 $\mathrm{mm}$ center-to-center spacing. The dormant spores (Fig. 7) exhibit center-to-center spacing similar to germinating spores (Fig. 8). This lamellar substructure appeared in all samples which 


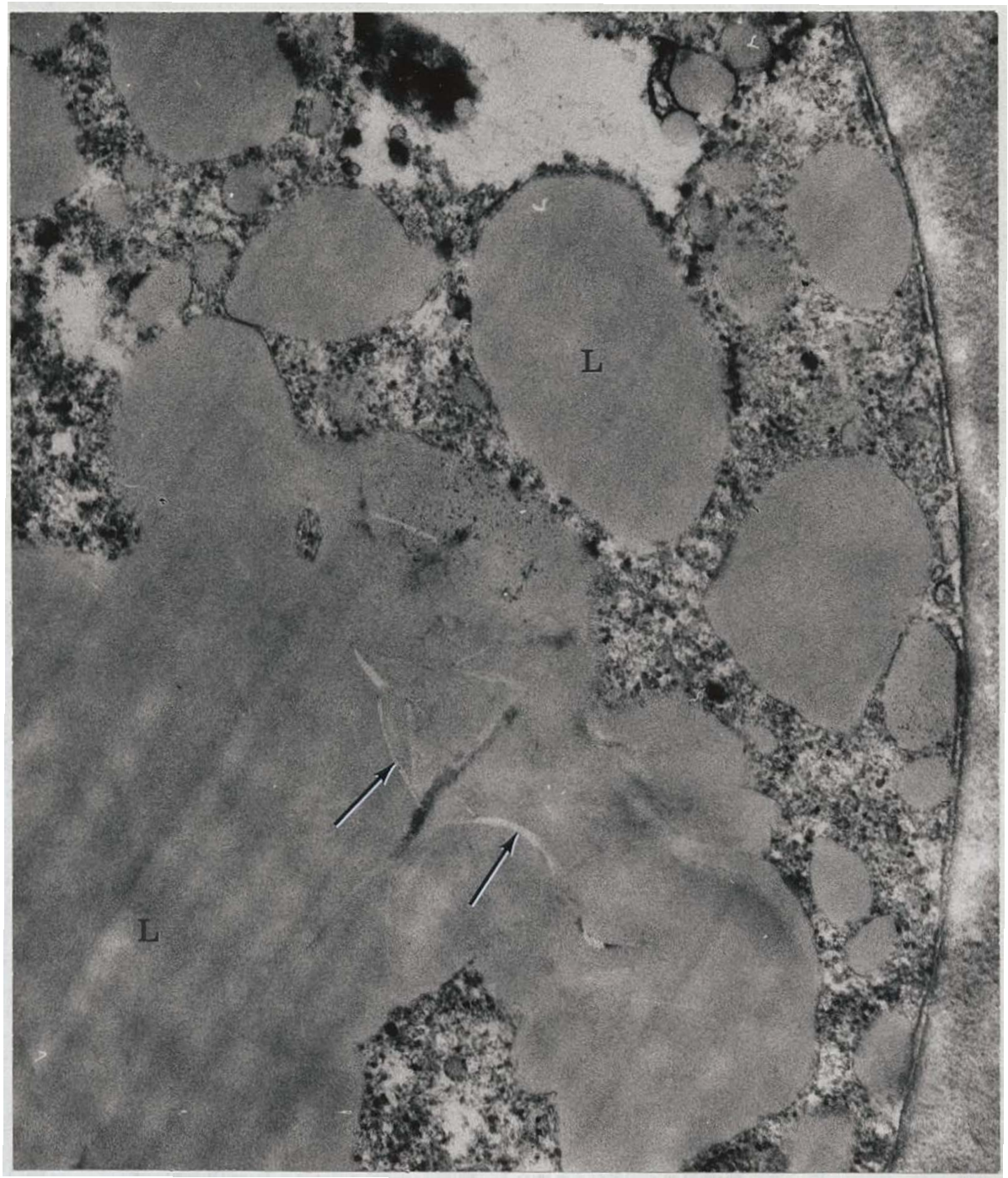

Fig. 4. Thin section of a lipid body (L) of a dormant teliospore. X27,000. Note the irregular electron dense patterns in the matrix of the lipid body (arrows). 


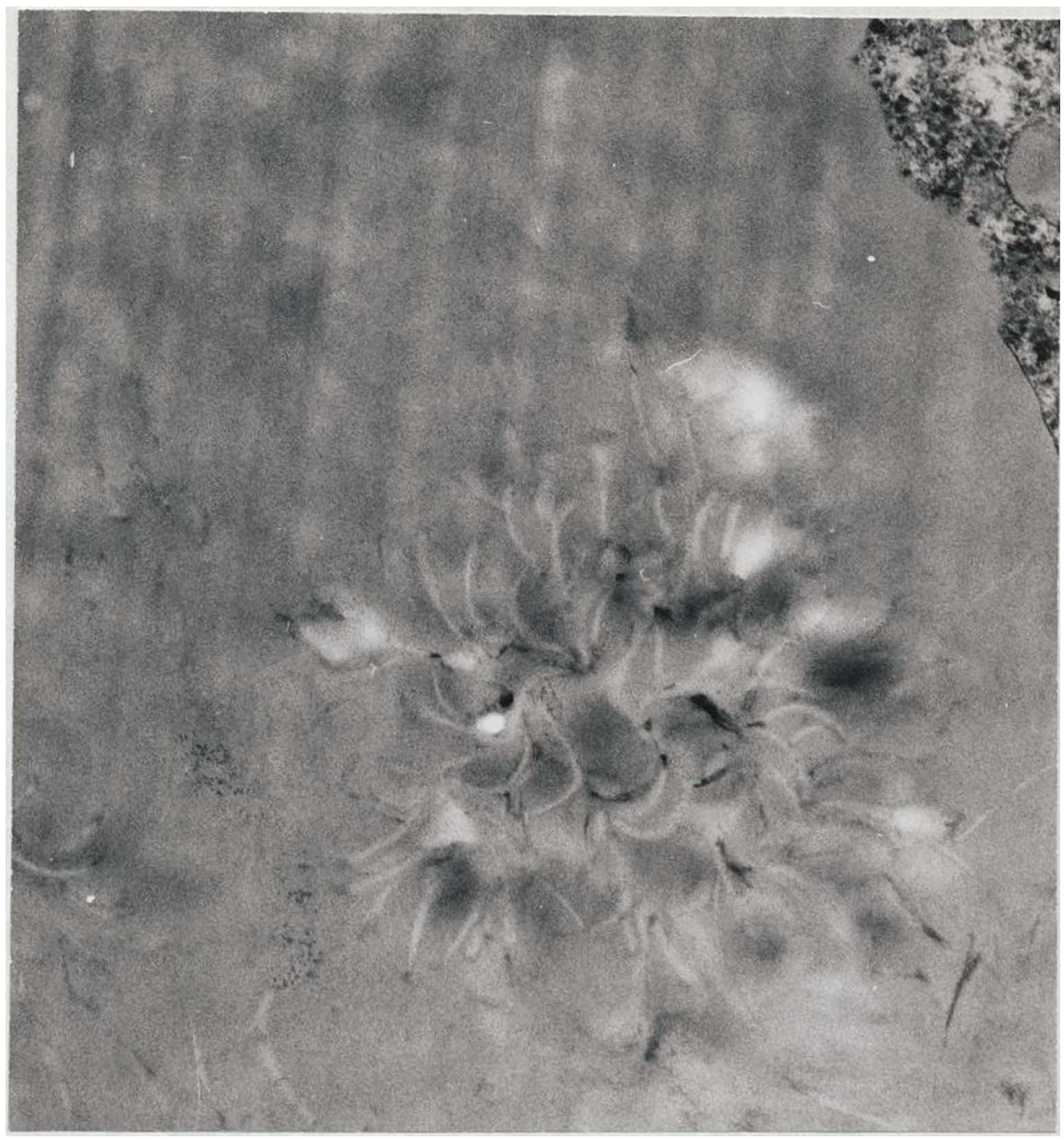

Fig. 5. Thin section of a lipid body of a dormant teliospore. X27,000. Note the "mop-7ike" structure which appears only rarely within the matrix of lipid bodies prepared in this manner. 


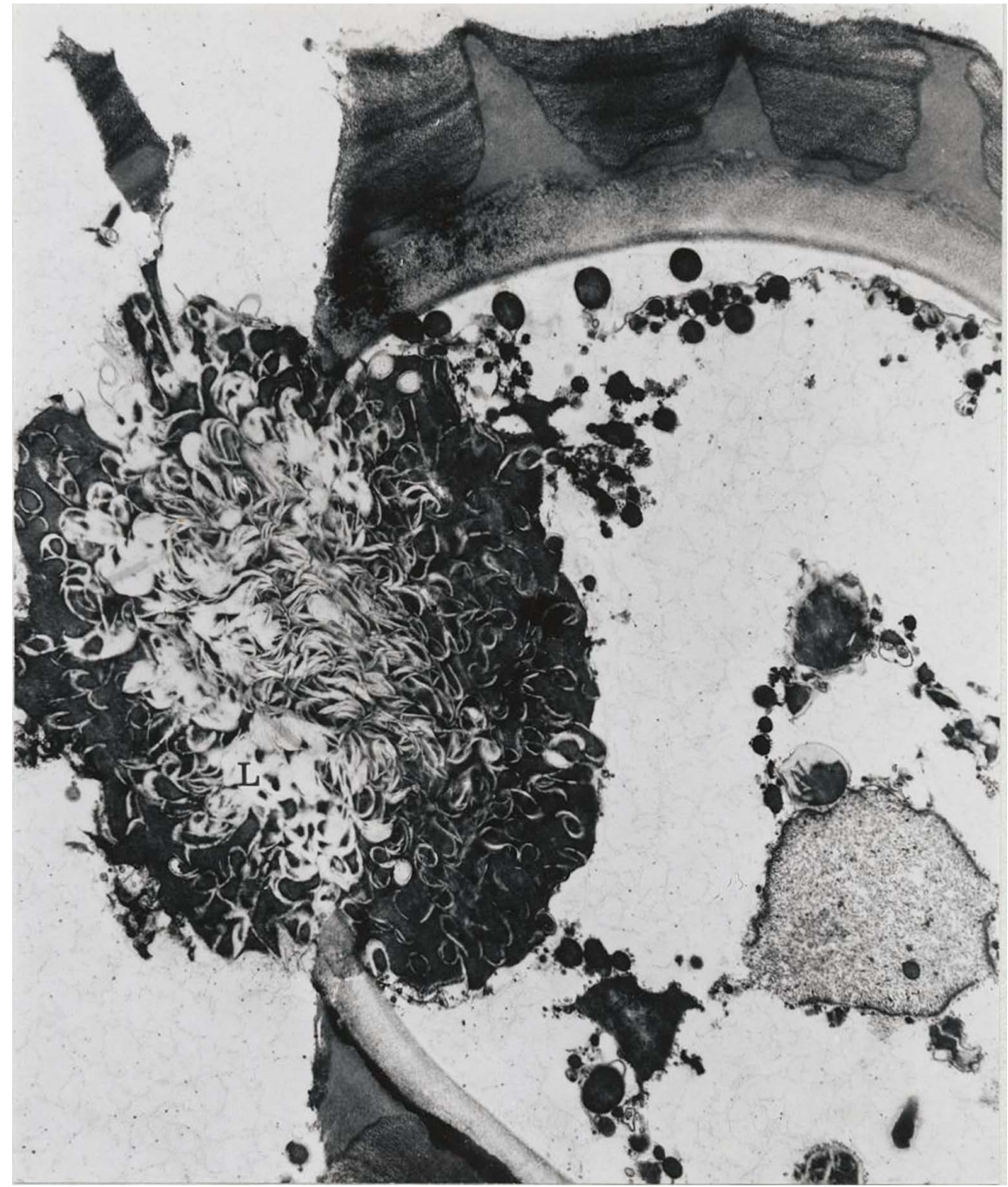

Fig. 6. Thin section of a dormant teliospore which was not prefixed in buffered glutaraldehyde-acrolein. X10,800. Note the massive "mop-like" substructure within the lipid body (L). 
were not prefixed prior to frozen sectioning. The prefixation treatment appears to stabilize the lipid bodies. The lamellar substructure is not commonly evident. Whereas, with unfixed spores lipid bodies commonly have distinct and numerous lamellar structures. 


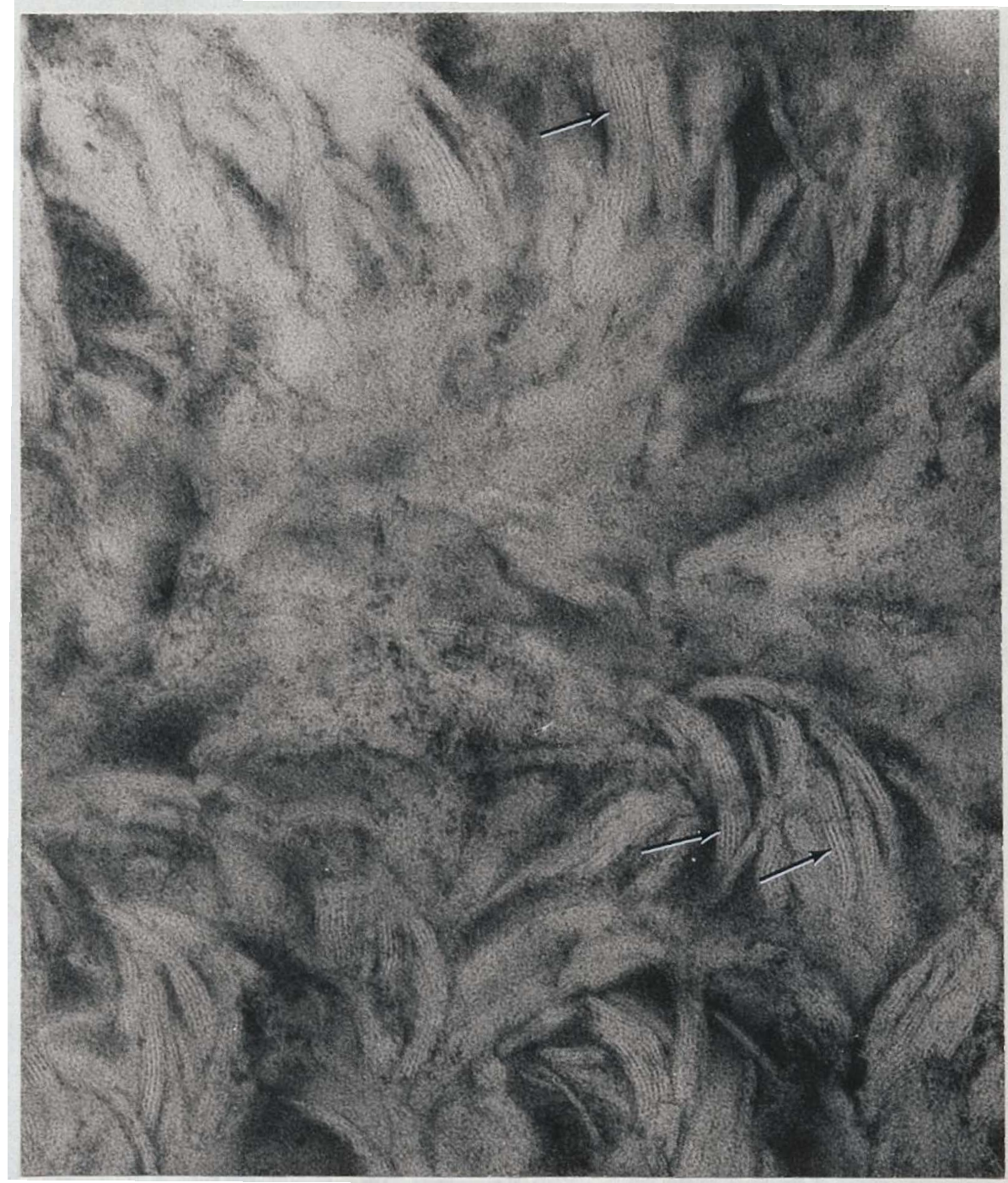

Fig. 7. Thin section of a Tipid body of a dormant teliospore which was not prefixed. X100,000. Note the distinct lamellar substructure (arrows) and the 6-10 nm center-to-center spacing of the lamellae. 


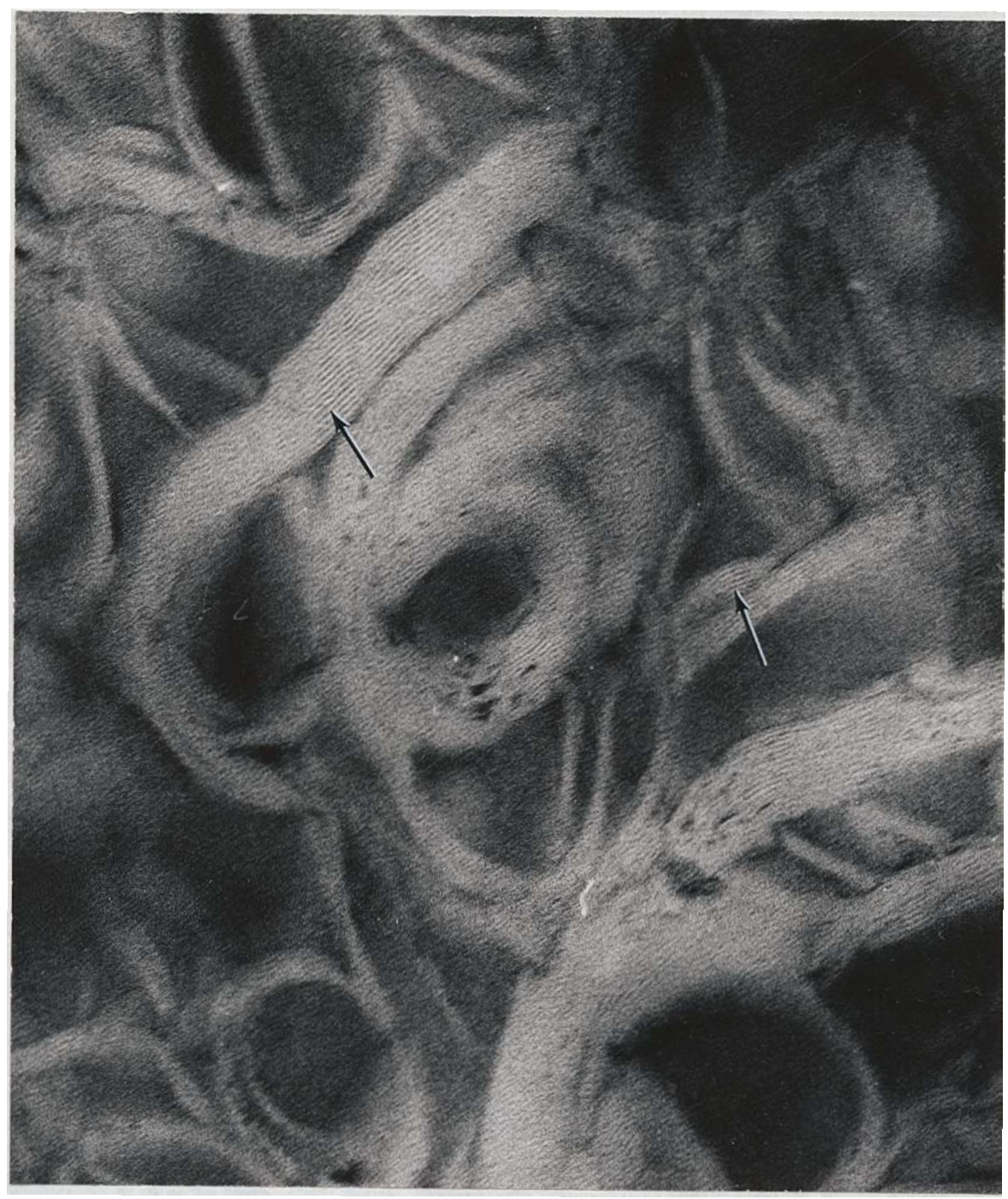

Fig. 8. Thin section of a 7 ipid body of a germinating teliospore which was not prefixed. $\times 100,000$. Note the distinct lamellar substructure (arrows) and the 6-10 nm center-to-center spacing of the lamellae as seen in the dormant teliospores. 


\section{LITERATURE CITED}

1. Allen, J. V., W. M. Hess, and D. J. Weber. 1971. U7trastructural investigations of dormant Tilletia caries teliospores. Mycologia 63:144-156.

2. Buttrose, M. S. and J. G. Swift. 1973. Inclusions within lipid droplets in some plant seeds. Protoplasma 78:471-476.

3. Dangeard, P. A. 1922. Sur 7a structure de la cellule chez les Ires. C. R. Acad. Sci. 175:7-12.

4. Gardner, J. S., J. V. Allen, and W. M. Hess. 1975. Fixation of dormant Tilletia teliospores for thin sectioning. Stain Tech. $50: 347-350$.

5. Gardner, J. S. and W. M. Hess. 1975. Ultrastructure of lipid bodies of Tilletia teliospores. Amer. J. Bot. 65:S27.

6. Hess, W. M. 1966. Fixation and staining of fungus hyphae and host plant root tissue for electron microscopy. Stain Tech. $41: 27-35$.

7. Jacks, T. J., L. Y. Yatsu, and A. M. A7tschul. 1967. Isolation and characterization of peanut spherosomes. Plant Physiol. 42:585-597.

8. Kwiatkowska, M. 1973. Half-unit membranes surrounding osmiophilic granules (lipid droplets) of the so-called lipotubuloid in Ornithogalum. Protop 7 asma 77:473-476.

9. Schwarzenbach, A. M. 1971, Observations on spherosomal membranes. Cytobiologie $4: 145-147$.

10. Yatsu, L. Y. and T. J. Jacks. 1972. Spherosome membranes.

Plant Physiol. 49:937-943. 
APPENDIX 2

LITERATURE REVIEW 


\section{LITERATURE REVIEW}

Many investigators have been interested in fungal spores and the processes which they undergo during germination. Some investigators have been concerned with physiological problems white others have studied the ultrastructural changes which take place during germination. Hess (26) and Hawker (21) have written excellent reviews with emphasis upon ultrastructural changes. In this literature review I have attempted to correlate some of the physiological and ultrastructural changes which occur during germination.

In genera 1, germination is defined as the transformation of a relatively inactive spore to the highly active vegetative thallus. One of the most obvious and usual differences between spores and vegetative stages is in the wall. Spores often have ornamented walls whereas vegetative hyphae lack ornamentation. For example, teliospores of some smut fungi are highly reticulated (28). Hawker and McV. Abbott (22) showed that two species of Rhizopus have reticulate sporangiospores. Hess and Weber (27) reported that dormant spores of Rhizopus arrhizus contain deep furrows and prominent ridges and Hawker et al. (23) showed that conidia of a species of Cunninghamella have protruding spines.

There is also a wide variation in thickness and number of layers in the spore wall. However, walls of vegetative stages of fungi usually are thinner and less complex (41). Spore walls range from two layers to four wall layers $(6,7,23,33)$. Graham (17) 
identified five wall layers in Tilletia controversa teliospores by use of histochemical techniques. U1trastructurally, four distinct layers were reported (2). As can easily be seen, spore walls form a very good protective coat for the dormant organism. In order to germinate, germ tubes penetrate the outer layers of the spore wall. This mechanism will be discussed later.

The total process of germination has been divided into two stages by Bartnicki-Garcia et al. (5); spherical growth; and emergence of a germ tube. These authors deliberately avoided the term swelling because significant growth takes place in most spores prior to germ tube emergence. However, swelling is the morphological change observed.

Hawker and Hendy (24) reported swelling in Botrytis cinerea as the first visible stage in germination. Gilbertella (7) and Aspergillus conidia (6) also swe11. During the swelling stage, the outer wal1 layer of Aspergillus fumigatus stretches and disintegrates (12). Several other spores follow a similar pattern $(22,34)$. In Linderina pennispora the outer wall is broken by the pressure of the protoplast as it swells (46). This breakdown of the spore wall greatiy facilitates germ tube emergence.

Walkinshaw et al. (45) reported that germination of rust spores involyed mainly an uptake of water. Seale (40) reasoned that spores are often in hygroscopic equilibrium with the environment and must absorb water to initiate the complex biochemical events leading to germination.

Some spores have additional requirements for initiation of germination. For example, some spores require exogenous carbon and 
nitrogen in order for swelling and germination to occur (12, 14, 31, 32). Ekundayo (14) found that viable spores which were suspended in heavy water would exchange heavy water for the normal water in the spore but swelling and germination would not take place. This substantiates the work of Bartnicki-Garcia et al. (5) who proposed that spherical growth is a more correct term for the initial stage of germination than simple swelling.

It appears however, that spherical growth is not a prerequisite for germination in all spores. Cassone et al. (13) reported that swelling was not obseryed preceding or accompanying blastospore germination of Candida albicans blastospores.

Other changes which support the spherical growth proposal are those which occur within the spore. By the time of germ tube emergence, the dry weight of Rhizopus arrhizus sporangiospores increases about $500 \%$ (14). There is obviously a tremendous amount of synthesis which takes place during the initial stages of germination.

One of the first changes is the increased rate of respiration (44L. Along with this are increases in the number of mitochondria $(12,24,41)$. Ungerminated spores contain varying numbers of mitochondria $(23,33)$ usually fewer than in the germinated state. These mitochondria may be large and contorted (22) or they may be spherical with few cristae (27), but as germination proceeds, the mitochondria increase in number by division. They also become smooth and regular, and the number of cristae increases.

Many spores contain a large number of lipid bodies $(1,2,23$, 36). These lipid bodies decrease in number or disappear completely during germination $(20,37,41)$. Much of the energy needed for 
germination processes is supplied by lipid utilization (45). McKeen proposed that additional water is supplied for germination by the oxidation of lipid molecules. Large amounts of hydrogen in these molecules are then oxidized to form the water for use during germination.

A11 spores do not completely use up their lipid bodies. For example, the lipid bodies in swollen and germinated sporangiospores of Rhizopus arrhizus do not appear to be different in size or quantity than in dormant spores (27). In other cases, there is an increase in the total lipid content as germination occurs (1).

Dormant spores contain very little if any endoplasmic reticulum $(24,33,41)$. The endoplasmic reticulum which is present is found in small strands close to the cytoplasmic periphery $(10,16$, 38). As germination progresses, the endoplasmic reticulum becomes visible (15) and in some organisms becomes long strands (10) or multiple sheets more centrally arranged (38).

Dormant spores contain varying numbers of nuclei depending upon the species $(10,15,24,33)$. In some species nuclear replication occurs during germination $(11,24)$ while in other nuclear division is delayed until considerable elongation occurs (1).

Spore germination is accompanied by progressive vacuolization $(5,10,24)$. Vacuoles may be formed as a result of 1 ipid utilization (5) or as contents flow from the spore during germ tube elongation $(24)$.

Dense inclusions are present in some dormant spores (10). It was suggested by Buckley et al. (10) that these inclusions provide material for the assembly of the membranous organelles during 
germination. Other spores have vesicles which appear to be associated with single cisternae or cisternal rings in both germinated and ungerminated spores $(1,8)$. Perhaps the vesicles have functions similar to the proposed functions for inclusion bodies.

Several biochemical changes occur during the spherical growth period, Protein synthesis may be detected very shortly after water uptake $(39,43,44)$. This synthesis is possible because of the presence of preformed mRNA and tRNA in the dormant spores $(9,42)$. Van Etten et al. (44) reported that protein and RNA synthesis began within the first 30 minutes and rapidly increased throughout the germination process. A11 three types of RNA (ribosomal, transfer, and messenger) initiate synthesis within this time period. Although DNA synthesis begins later, it starts before the spore is fully swollen. Some other spores do not exhibit protein synthesis as the first step (3), however it starts long before germ tube emergence. As growth and germination continue, there are several problems which must be overcome. The first is the formation of vegetative hyphae. How will they be formed? What will be the origin of the vegetative wall? In his review of spore walls, BartnickiGarcia (4) described two very different mechanisms for vegetative wall formation during germination; the vegetative wall is derived from an extension of the spore wall, seen in the higher fungi, and de novo synthesis of a vegetative wall under the spore wall, seen in the Phycomycetes. For the higher fungi, it has been well documented that the germ tube wall is formed by the extension of the original spore walls $(15,18,24,33,35,37)$. There is clear evidence that new walls are formed de novo in the Phycomycetes $(5,7,8,11,14,22)$. 
If the higher and lower fungi can be separated based upon the deposition of a new wal1 layer which forms the germ tube wal1, evolutionary relationships may be more easily determined.

There are several examples where higher fungi do not appear to deposit new spore wal1s prior to germination $(6,13,15,19,29$, 30). Florance et al. (16) also indicated that the germ tube originated from the innermost of two new wall layers. However, these authors stated that they did not believe that de novo synthesis had occurred. They agreed with Bartnicki-Garcia (4) that the layering was probab7y due to changes within the existing wall brought about by imbibition of water and increased metabolic activity and not synthesis of new wall layers. A similar observation was made by Hawker et al. (23). Another possibility is that the new wall layer is laid down after germination (38).

The second problem which must be overcome is the penetration of the spore coat by the germ tube. Three major methods may be possible; first, the outer spore walls may be ruptured mechanically by the emerging germ tube (23), second a combination of mechanical force and enzymatic action (13) or simple 1ytic action of enzymes (29) may allow germ tube emergence. The third method was discussed above and includes the rupture of the spore walls. Some spores have helped to solve the problem of wall penetration by producing one or more pores in the spore wall $(40,45)$.

An important role of spore walls in the physiology of dormancy has recently been discovered. Trehalase was found in the innermost wall of Neurospora ascospores while trehalose is located within the cytoplasm (25). Thus the compounds are kept physically separated 
until the uptake of water when the plasma membrane becomes more permeable to trehalose and contact between the enzyme and substrate is made.

From these obseryations it is clear that the germination process is very complex. As more is known about structure and function of organelles and biochemicals in spores it is becoming evident that much more work will have to be done before all processes are known. 


\section{LITERATURE CITED}

1. Aitken, W. Brent and Donald J. Niederpruem. 1970. U1trastructural changes and biochemical events in basidiospore germination of Schizophyllum commune. J. Bacteriol. 104:981-988.

2. Allen, J. V., W. M. Hess, and D. J. Weber. 1971. U1trastructural investigations of dormant Tilletia caries. Mycologia 63:144-156.

3. Bainbridge, B. W. 1971. Macromolecular composition and nuclear division during spore germination in Aspergillus nidulans. J. Gen. Microbio1. 66:319-325.

4. Bartnicki-Garcia, S. 1968. Cell wall chemistry, morphogenesis, and taxonomy of fungi. Ann. Rev. Microbiol. 22:87-108.

5. Bartnicki-Garcia, S., Nancy Nelson, and E. Cota-Robles. 1968. Electron microscopy of spore germination and cell wall formation in ilucor rouxii. Arch. Mikrobio1. 63:242-255.

6. Border, D. J. and A. P. J. Trinci. 1970. Find structure of the germination of Aspergillus nidulans conidia. Trans. Br. Mycol. Soc. 54: $143-152$.

7. Bracker, C. E. and Norma K. Halderson. 1971. Wall fibrils in germinating sporangiospores of Gilbertella persicaria (Mucorales). Arch. Mikrobiol. 77:366-376.

8. Bracker, C. E. 1971. Cytoplasmic vesicles in germinating spores of Gilbertella persicaria. Protoplasma 72:381-397.

9. Bramb7, R. M. and James L. Van Etten. 1970. Protein synthes is during fungal spore germination $V$. Evidence that the ungerminated conidiospores of Botryodiplodia theobromae contain messenger ribonucleic acid. Arch. Biochem. Biophys. 137:442452.

10. Buckley, P. M., V. E. Sjaholm, and N. F. Sommer. 1966. Electron microscopy of Botrytis cinerea conidia. J. Bacteriol. 91: 2037-2044.

11. Buckley, P. M., N. F. Sommer, and T. T. Matsumoto. 1968. U1 trastructural details in germinating sporangiospores of Rhizopus stolonifer and Rhizopus arrhizus. J. Bacteriol. 95:2 $\overline{365-2373}$. 
12. Campbe11, C. K. 1971. Fine structure and Physiology of conidial germination in Aspergillus fumigatus. Trans. Brit. Mycol. Soc. $57: 398-402$.

13. Cassone, A., N. Simonetii, and V. Strippoli. 1973. Ultrastructural changes in the wall during germ tube formation from blastospores of Candida albicans. J. Gen. Microbiol. 77:417426.

14. Ekundayo, J. A. 1966. Further studies on germination of sporangiospores of Rhizopus arrhizus. J. Gen. Microbiol. 42: 283-291.

15. Fletcher, J. 1971. Fine structural changes during germination of conidia of Penicillium griseofulvum Dierckx. Ann. Bot. $35: 447-449$.

16. Florance, E. R., H. C. Denison, and T. C. Allen Jr. 1972. U1 trastructure of dormant and germinating conidia of Aspergillus nidulans. Mycologia 64:115-123.

17. Graham, S. 0. 1960. The morphology and a chemical analys is of the teliospore of the Dwarf Bunt fungus, Tilletia controversa. Mycologia $51: 97-110$.

18. Grove, S. N., K. B. Oujezdsky, and P. J. Szaniszlo. 1973. Budding in the dimorphic fungus Phialophora dermatitidis. J. Bacterio1. 115:323-329.

19. Gu11, K. and A. P. J. Trinci. 1971. Fine structure of spore germination in Botrytis cinerea. J. Gen. Microbiol. 68:207220.

20. Gunasekaran, M., D. J. Weber, and W. M. Hess. 1972. Changes in lipid composition during spore germination of Rhizopus arrhizus. Trans. Brit. Mycol. Soc. 59:241-248.

21. Hawker, L. E. 1971. U1 trastructure of fungus spores, with special reference to changes taking place during germination. J. Ind. Bot. Soc. "Golden Jubilee Volume" 50A:12-25.

22. Hawker, L. E. and P. McV. Abbott. 1963. An electron microscope study of maturation and germination of sporangiospores of two species of Rhizopus. J. Gen. Microbiol. 32:295-298.

23. Hawker, L. E., B. Thomas, and A. Beckett. 1970. An electron microscope study of structure and germination of conidia of Cunninghame11a elegans Lender. J. Gen. Microbiol. 60:181-189.

24. Hawker, L. E. and R. J. Hendy. 1963. An electron microscope study of germination of conidia of Botrytis cinerea. J. Gen. Microbio1. 33:43-46. 
25. Hecker, Lanny I. and Alfred S. Sussman. 1973. Localization of trehalase in the ascospores of Neurospora: relation to ascospore dormancy and germination. J. Bacteriol. 115:592-599.

26. Hess, W. M. 1973. U1trastructure of fungal spore germination. Kyoto $8: 71-84$.

27. Hess, W. M. and D. J. Weber. 1973. U1 trastructure of dormant and germinated sporangiospores of Rhizopus arrhizus. Protoplasma 77:15-33.

28. Khanna, Asha, M. M. Payak, and S. C. Mehta. 1966. Teliospore morphology of some smut fungi. I. Electron microscopy. Mycologia 58:562-569.

29. Marchant, R. 1966. Fine structure and spore germination in Fusarium culmorum. Ann. Bot. 30:447-445.

30. Marchant, R. 1966. Wall structure and spore germination in Fusarium culmorum. Ann. Bot. 30:821-830.

31. Marchant, R. and Monica F. White. 1966. Spore swelling and germination in Fusarium culmorum. J. Gen. Microbio1. 42: 237-244.

32. Martin, J. F. and G. Nicolas. 1970. Physiology of spore germination in Penicillium notatum and Trichoderma lignorum. Trans. Brit. Mycol. Soc. 55:147-148.

33. Martin, J. F., F. Uruburu, and J. R. Villanueva. 1973. U1trastructural changes in the conidia of Penicillium notatum during germination. Can. J. MicrobioT. 19:797-807.

34. Martin, J. F., G. Nicolas, and J. R. Villanueva. 1973. Chemical changes in the cell walls of conidia of Penicillium notatum during germination. Can. J. Microbiol. 19:789-796.

35. McCoy, C. E., A. E. Girard, and J. M. Kornfeld. 1971. Fine structure of resting and germinating Penicillium chrysogenum conidiospores. Protoplasma 73:443-456.

36. Mckeen, W. E. 1970. Lipid in Erysiphye graminis hordei and its possible role during germination. Can J. Microbiol. 16:10411044.

37. Remsen, C. C., W. M. Hess, and M. M. A. Sassen. 1967. Fine structure of germinating Penicillium megasporum conidia. Protop 1asma 64:439-451.

38. Richmond, D. V. and R. J. Pring. 1971. Fine structure of germinating Botrytis fabae Sardina conidia. Ann. Bot. 35:493-500. 
39. Rousseau, Paul and Harlyn 0. Halsorson. 1973. Macromolecular synthesis during the germination of Saccharomyces cerevisiae spores. J. Bacteriol. 113:1289-1295.

40. Seale, Thomas. 1973. Life cycle of Neurospora crassa viewed by scanning electron microscopy. J. Bacterio1. 113:1015-1025.

41. Sussman, Alfred S. and H. A. Douthit. 1973. Dormancy in microbial spores. Ann. Rev. P1. Phys. 24:317-352.

42. Van Etten, J. L., R. Kent Koski, and M. M. El-01emy. 1969. Protein synthesis during fungal spore germination. IV. Transfer ribonucleic acid from germinated and ungerminated spores. J. Bacteriol. 100:1182-1186.

43. Van Etten, J. L., Henry R. Roker, and Eric Davies. 1972. Protein synthesis during fungal spore germination: Differential protein synthesis during germination of Botryodiplodia theobromae spores. J. Bacteriol. 112:1029-1031.

44. Van Etten, J. L., L. A. Butla Jr., and G. St. Julian. 1974. Physiological and morphological correlation of Rhizopus stolonifer spore germination. J. Bacteriol. 117:882-887.

45. Walkinshaw, C. H., J. H. Hyde, and J. van Zandt. 1967. Fine structure of quiescent and germinating aeciospores of Cronartium fusiforme. J. Bacteriol. 94:245-254.

46. Young, T.W. K. 1971. U1trastructure of the wall of the germinating sporangiospore of Linderina pennispora (Mucorales). Ann. Bot. 35:183-191. 


\title{
FIXATION OF DORIAANT TILLETIA TELIOSPORES \\ FOR TIIIN SECTIONING
}

\author{
John Scott Gardner \\ Department of Botany and Range Science \\ M.S. Degree, Apri1 1976
}

\begin{abstract}
Dormant Tilletia caries teliospores in fixative solution or distilled water were frozen onto specimen chucks of an FTS Sorval1Christensen frozen thin sectioner and cut or fractured at various temperatures $(-20$ to $-75 \mathrm{C})$ and thickness settings $(10,75,20$, and 25 um). Cytoplasm of dormant spores was well preserved and orcanelles were found to differ from those of germinated spores in morphoiogy.

Irregular electron dense and electron opaque areas of lipid bodies were sometimes evident in dormant and germinating Iilletia caries teliospores. When dormant teliospores were sectioned in buffered fixative, lipids had an appearance similar to lipids in thin sections of germinated teliospores. When dormant and germinating teliospores were sectioned in frozen distilled water and subsequently fixed, "mop-like" structures were evident. The "r:op-like" structures were made up of a lamel1ar substructure with 6-10 nm center-to-center spacing. Lipid bodies of dormant and germinating teliospores often appear to have half-unit membranes surrounding them.
\end{abstract}

